\title{
Facilitating the Teaching of Product Development
}

\section{Dr. Claes Fredriksson, Granta Design, Cambridge (UK)}

Currently working as Senior Materials Education Consultant at Granta Design in Cambridge, UK. Until recently Program Director for a Master's Programme in Manufacturing Engineering at University West in Sweden. Experience in teaching subjects like Materials Science \& Technology and Environmental Technology to students of mechanical engineering at the department of Engineering Science since 1999.

\section{Mr. Mats Eriksson, Univeristy West}

Ms. Hannah Melia, Granta Design, Ltd.

Hannah Melia is the leader of the Teaching Resources Team at Granta Design, Cambridge, UK. She has a Post Graduate Certificate in Design, Manufacturing and Management and a Bachelor's degree in Materials Science and Metallurgy from the University of Cambridge, England and has worked in teams on various parts of product development, in different industries for 15 years. 


\title{
Facilitating the Teaching of Product Development
}

\begin{abstract}
Product Development is a key topic for many engineering courses and educational programmes. The Product Development Process, as applied in industry, consists of all the necessary steps to bring a new or redesigned product to the market. Although the process is practiced in many different ways, depending on, for instance, company size and customer requirements, there are many common elements. These need to be covered by University teaching to prepare students for jobs in industry. This paper considers how students can be supported to make open, creative and well informed decisions in several stages of the product development process.
\end{abstract}

A teaching approach suitable for the product development process is described and investigated. The pedagogic context of the approach is project based learning in small student groups with short regular meetings with an instructor for consultation and supervision. The educational resources that are used consist of a combination of materials and manufacturing process databases, eco-performance indicators, as well as computer based selection and visualization tools.

The methodology has been tested in a class of third year undergraduate students of Mechanical Engineering taking a course in Product Development. One group of 4 students was followed during the development of a liquid container also serving as a construction element for use in developing countries or in disaster areas. Specific details of the teaching approach, the use of computer resources as a project tool, examination of the project and assessment of the results by the instructor and by the students are reported.

It was found that the computer based tools employed could be used in a generic manner to facilitate the learning related to the following steps of a product development process:

- specification of product function and requirements,

- screening and scoring (ranking) of concepts,

- optimization of properties for the final design, including manufacturing selection and costing, as well as

- evaluation of properties of the final product to be used by marketing

We believe that the findings are useful for many different directions within product development, for example Design for $X$ (DfX) which is commonly used to represent different design focuses. In particular, X could stand for Manufacturing or Environment in our approach. Furthermore, the approach is compatible with Concurrent Engineering. 


\section{Introduction}

Product Development is important in many engineering courses and educational programmes. The Product Development Process, as applied in industry, is practiced in many different ways, depending on, for instance, product technology, company size and type of market. At University, general and systematic approaches to product development need to be covered to prepare students for various careers in industry.

The design process starts with the identification and specification of the product function ${ }^{1-2}$. The next step is the description of concepts, their elaboration into possible layouts, followed by refinement of the design and, finally, arriving at a specification, see Figure 1 . The ultimate goal is to enable manufacturing of a functional product meeting all design requirements.

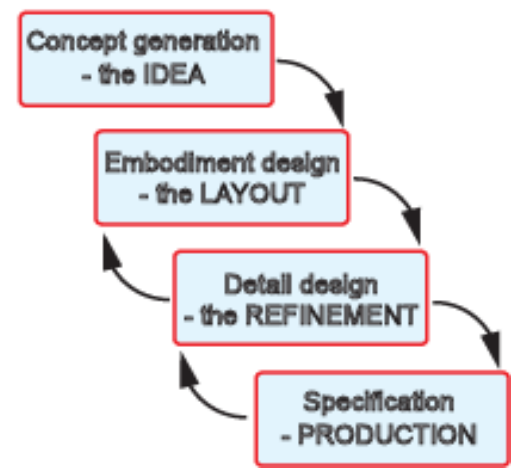

Figure 1. Simplified Design Process, adapted from flow chart of Pahl et al. ${ }^{1}$

One of the challenges during the development of a physical product is to balance the aspects of Function, Shape, Material and Process ${ }^{3}$, see Figure 2. This is emphasized, in particular, in Design for Manufacturing (and Assembly) ${ }^{4}$. It is important that software tools to present computer-based support in the product development process provides adequate links between materials, processes and shape during selection.

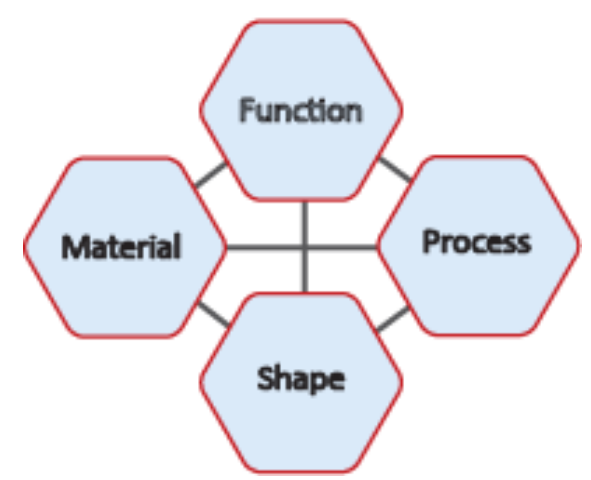

Figure 2. The interlinks between important parameters of design ${ }^{3}$ 
Since product development is creative, collaborative and usually performed under fixed timeframes, it appears suitable for project based learning in student groups. It can, of course, be supplemented with lectures and/or supervision. In Mechanical Engineering, it also offers a possibility to apply previous knowledge from, for instance, courses on Manufacturing or CAD. This has prompted us to develop and explore a methodology in a real student project.

The starting point for this paper is the use of an established software to support teaching in Engineering, Materials Science or Design along the lines discussed above. We consider the Standard edition of CES EduPack, software which was originally developed at the Engineering Department of Cambridge University (UK) ${ }^{3}$. This software is part of a family of tools used extensively for materials-related applications in industry and research (CES Selector and Granta $\mathrm{MI})^{5}$. Large enterprises, additionally, tend to innovate and test their own materials and store, analyse and use data about these alongside standard design data provided by materials producers. This data is contained in unique databases which are mined for information during product development. It is therefore important that engineering students are aware of such systems and can interact with them.

CES EduPack (henceforth referred to as the software) is well known at Universities for its capabilities in materials and process selection within technical design ${ }^{6}$. However, it supports Product Development in other ways too. At the heart of the software is the interactive visualization of properties in charts which are used to facilitate communication and understanding in the educational context. Another important feature is the built-in Eco Audit tool which is used to analyze carbon footprints and embodied energies even during the design process. This is particularly useful if Design for Environment is considered. Figure 3 summarizes the inputs to the design, linking them with features of the software on the right hand side. 


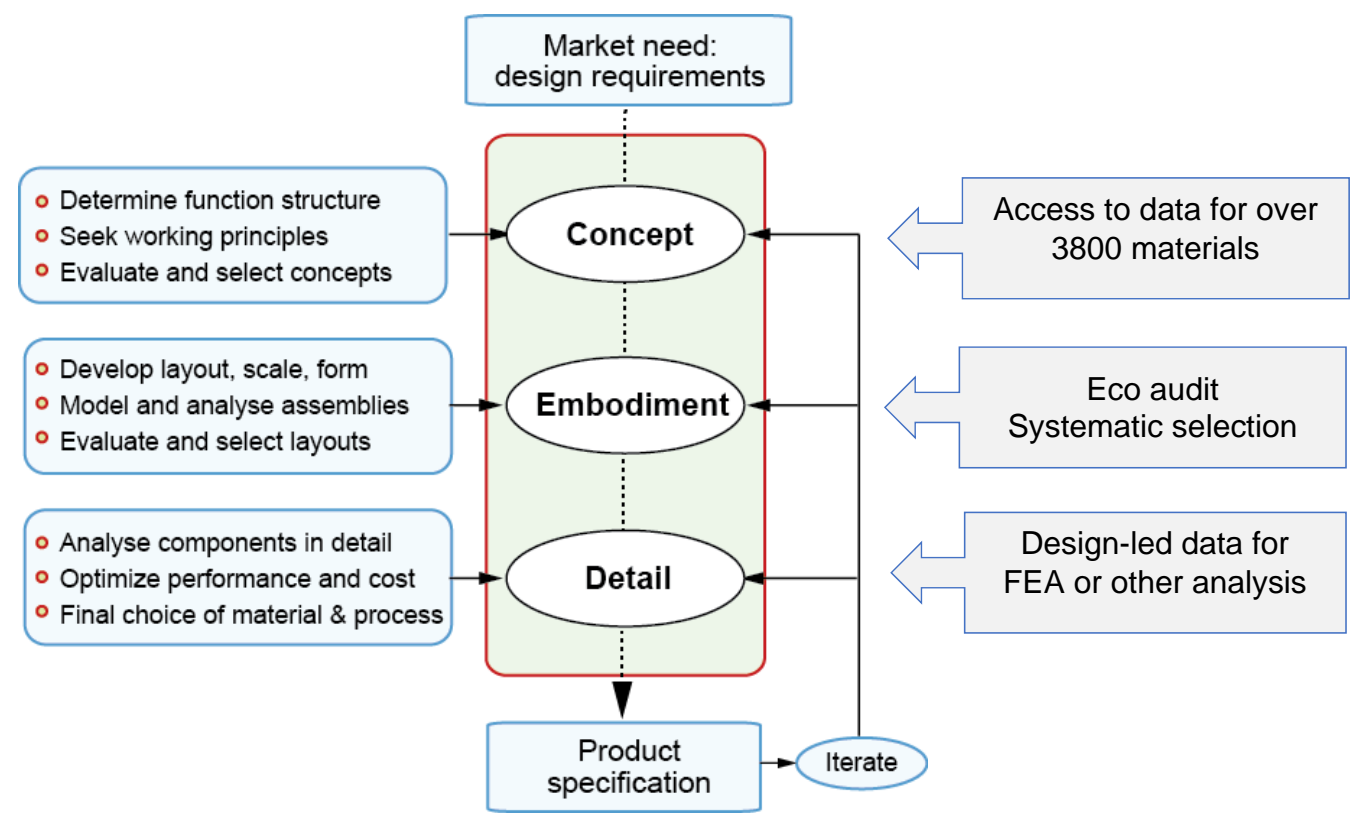

Figure 3. Core capabilities of CES EduPack, in relation to the technical design process ${ }^{3}$

We identify four key areas: (i) specification of product function and requirements, (ii) screening and scoring (ranking) of concepts, (iii) optimization of properties for the final design, including manufacturing selection and costing, as well as (iv) evaluation of properties of the final product to be used by marketing.

Our approach includes activities that push the limits at both ends of the technical design process (before the design requirements are fixed and after a product specification is proposed). The approach appears suitable in the wider context of product development (rather than technical design). The methodology was therefore tested in a class of third year undergraduate students of Mechanical Engineering. A small group was followed specifically in the creative product development teaching/learning process. Their project was the development of a liquid container also serving as a construction element for use in developing countries or in disaster areas. This implementation of the approach in a class on Product Development is described and discussed in sections 3.1-3.4. 


\section{Teaching Methodology and Assessment}

\section{Project based learning}

The teaching approach described and tested is one of project based learning, using the above mentioned software as a main resource during a product development process with weekly project consultation and supervision by the instructor. A group of four $3^{\text {rd }}$ year undergraduate students of mechanical engineering at University West (Sweden) participated in this case study. The monitored project group was one of eight groups in the class, all working on different products. The software had been introduced to the students in a previous course in Materials Science and Engineering.

The Product Development course ran part time for a total of 20 weeks. For the first part of the course, the students were given the task of identifying an opportunity for a new or substantially improved product, having some kind of sustainability profile. This opportunity was elaborated on according to the Ulrich-Eppinger model $^{2}$ for product development. The selection of concept for final design was based on how well it fulfilled requirements, as identified by the students through market analysis. All groups in the class had access to the software but the monitored group was selected since they chose to work on a relatively simple physical product (few components), where materials selection was a key factor. The use of the software for this group was observed and documented during the project. The other groups chose not to use the software to the same extent.

The examination of the project and assessment of the results by the instructor is carried out under an Outcome-Based Curriculum Framework, as specified by the Bologna process ${ }^{7}$. In this context, particular emphasis is put on constructive alignment ${ }^{8}$ between intended learning outcomes, as specified by the course syllabus; the teaching and learning activities within and outside of the classroom; and appropriate assessment of students at the end of the course, see Figure 4. The use of the software relates closely to Teaching and learning activities in this model.

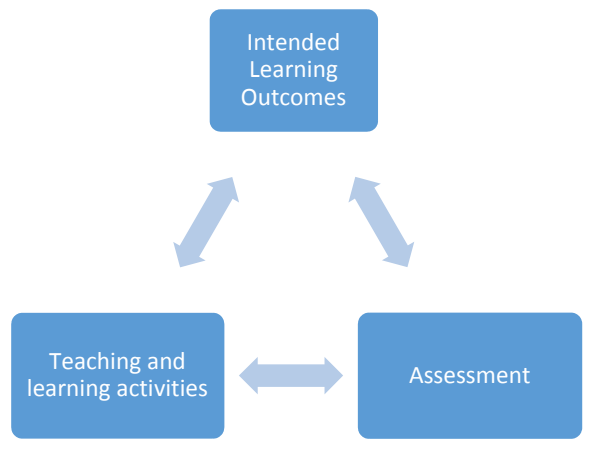

Figure 4. The concept of Constructive Alignment, as used by Biggs ${ }^{8}$ 


\section{Student assessment}

It must be emphasized that it is not the software that will assure fulfilment of intended learning outcomes (learning objectives), but rather how it is used, in conjunction with learning activities. This particular software is, however, designed to support learning outcomes relevant for product development and has successfully been used for this ${ }^{9-10}$. Although we believe that the software and associated teaching resources can support a wide range of learning outcomes, we suggest that the higher one aims in Bloom's Taxonomy ${ }^{11}$, the more important the role of the instructor effort is, as indicated symbolically by the length of the arrows in Figure 5.

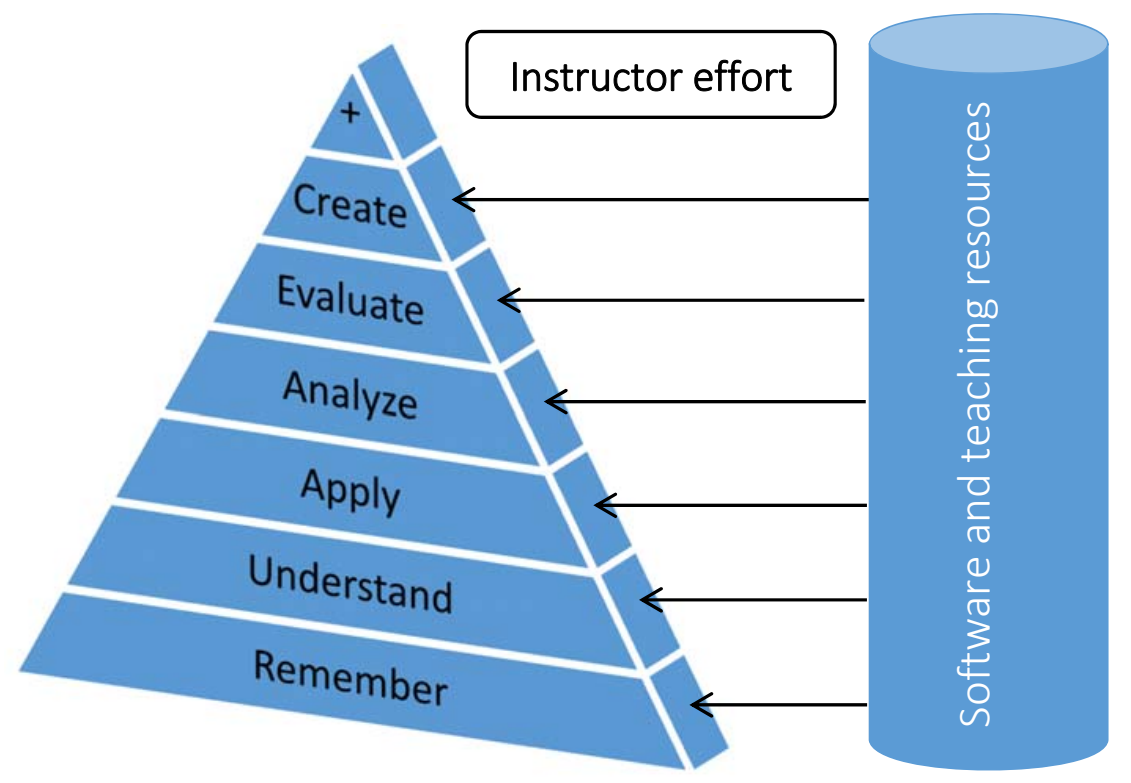

Figure 5. CES EduPack and educators supporting outcomes in Bloom's Taxonomy ${ }^{11}$

Three examples of intended learning outcomes in this particular course on Design and Product Development I and II are listed below. In order to pass, the students must demonstrate:

- Knowledge about product development tools and methods that facilitates a structured product development process

- Ability to perform a structured product development project

- Ability to critically evaluate the results obtained in relation to the completed project

As examples, we have chosen one learning outcome from each of the Skills-Knowledge-Attitudes categories used by MIT $^{12}$. These are in close agreement with the format used internally at the Department of Engineering Science of University West. The other intended learning outcomes (not mentioned here) relate to sustainability, presentation skills etc. 
The examination of the course is differentiated depending on which learning outcome to assess. Students' knowledge on product development theory is assessed through written exams containing questions on the contents of the course literature (textbooks and research papers). The ability of students to perform a structured development project, including to identify and solve problems, evaluate solutions as well as their use of tools and methods is evaluated and assessed in weekly meeting with the examiner. At these meetings, each student has to be report and reflect on the work done and results obtained. Finally, the work is summarized by the student groups in an extensive written report. The project is also presented orally to the class.

\section{Product Development Case Study using CES EduPack}

The methodology for (linked) materials and process selection was originally developed to support the basic steps in the technical design process, such as the one described in Figure 1. It is implemented in the selection tool of the software and it is described extensively elsewhere ${ }^{3,5}$. In this case study, we have tried an approach to explore the utility more broadly, supporting many aspects in the teaching of Product Development. Four areas are given in sections 3.1-3.4. In each section, we describe ideas for potential use of the software and comment on the results from the monitored project group, working on a multi-purpose liquid container.

\subsection{Specification of product function and requirements}

\section{Potential use of the software}

In most design processes, the starting point is the identification of a need that can be fulfilled with a new or modified product. In this paper, we consider the mechanical design of a physical product, where materials have to be selected. During the first stage of idea-creation, for instance by brainstorming, it is important to clarify the product specification with respect to function and design requirements. During the translation of these requirements into constraints and objectives, many properties have to be considered.

A large number of mechanical, thermal, electrical, optical and processability properties, as well as several durability properties, such as resistance to alkalis or acids exist and can also give inspiration for new products, if used as inputs during brainstorming. To support the creative process during innovation (before design specification) looking at the range of properties for materials, ideas based on extreme values of properties or gaps in properties that could be filled by hybrid materials can be generated. It can also be useful to look at typical uses for materials, a feature included in the data records of the software. This might trigger associations for high performance materials or give options for similar applications. An example relevant to the case study is shown in Figure 6. 


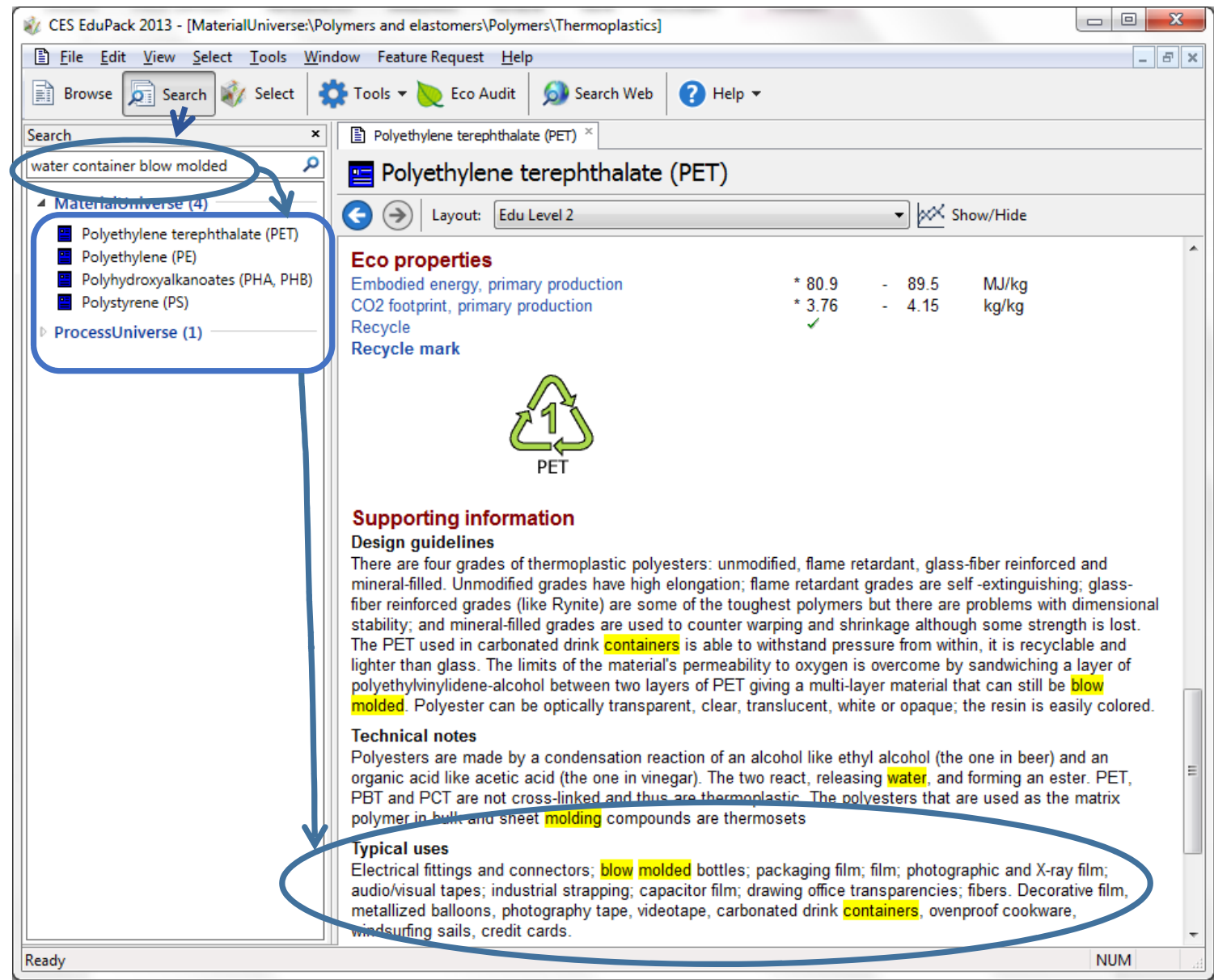

Figure 6. Example of data record showing typical uses of PET, one material that was identified by searching for "water container" and "blow molded". Listed candidates can be investigated.

Furthermore, it is very easy to create charts of property combinations in this software, for instance, strength per cost or stiffness per density. This flexibility is not commonly found in traditional product catalogues or data tables containing material properties and offer advantages. In Figure 7, a chart of Strength vs Carbon footprint (per volume) is shown as an example suitable for Eco Design. 


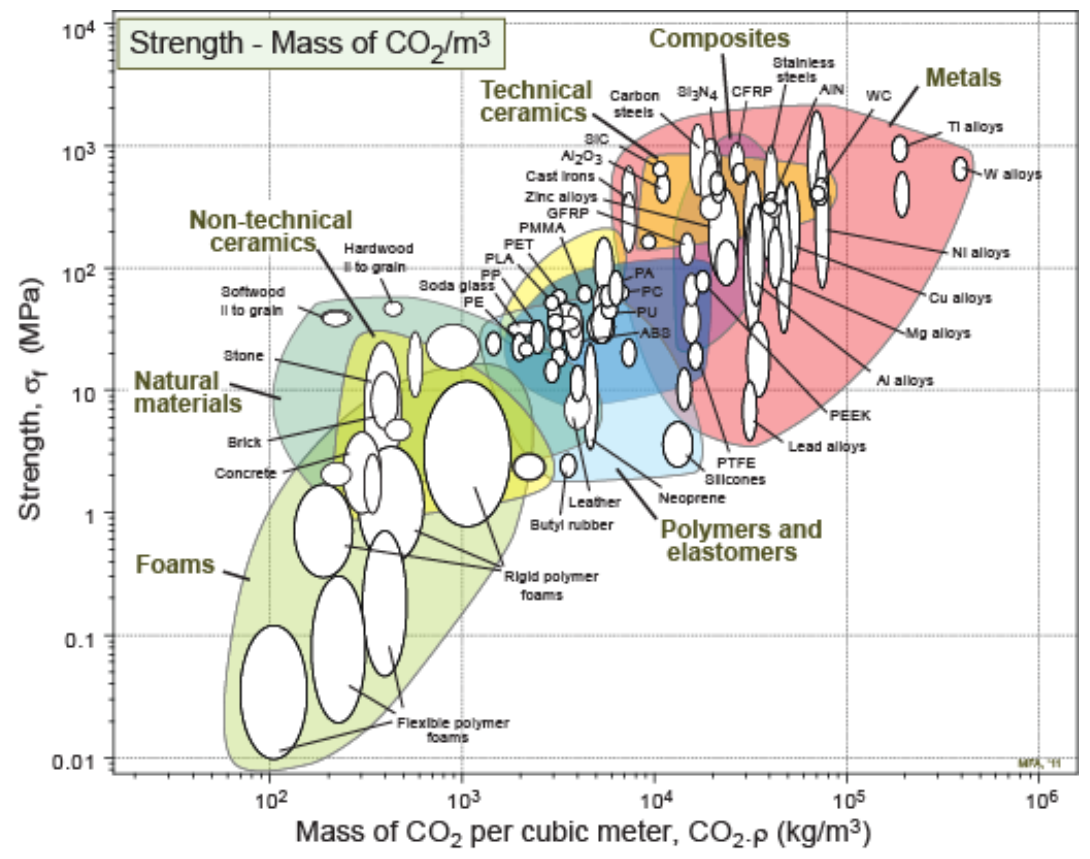

Figure 7. Example of property chart that might serve as inspiration for new products

\section{Student case study}

The identification of requirements by the students started with a thorough life cycle mapping of their product idea; a liquid container also serving as a construction element, see Figure 8.

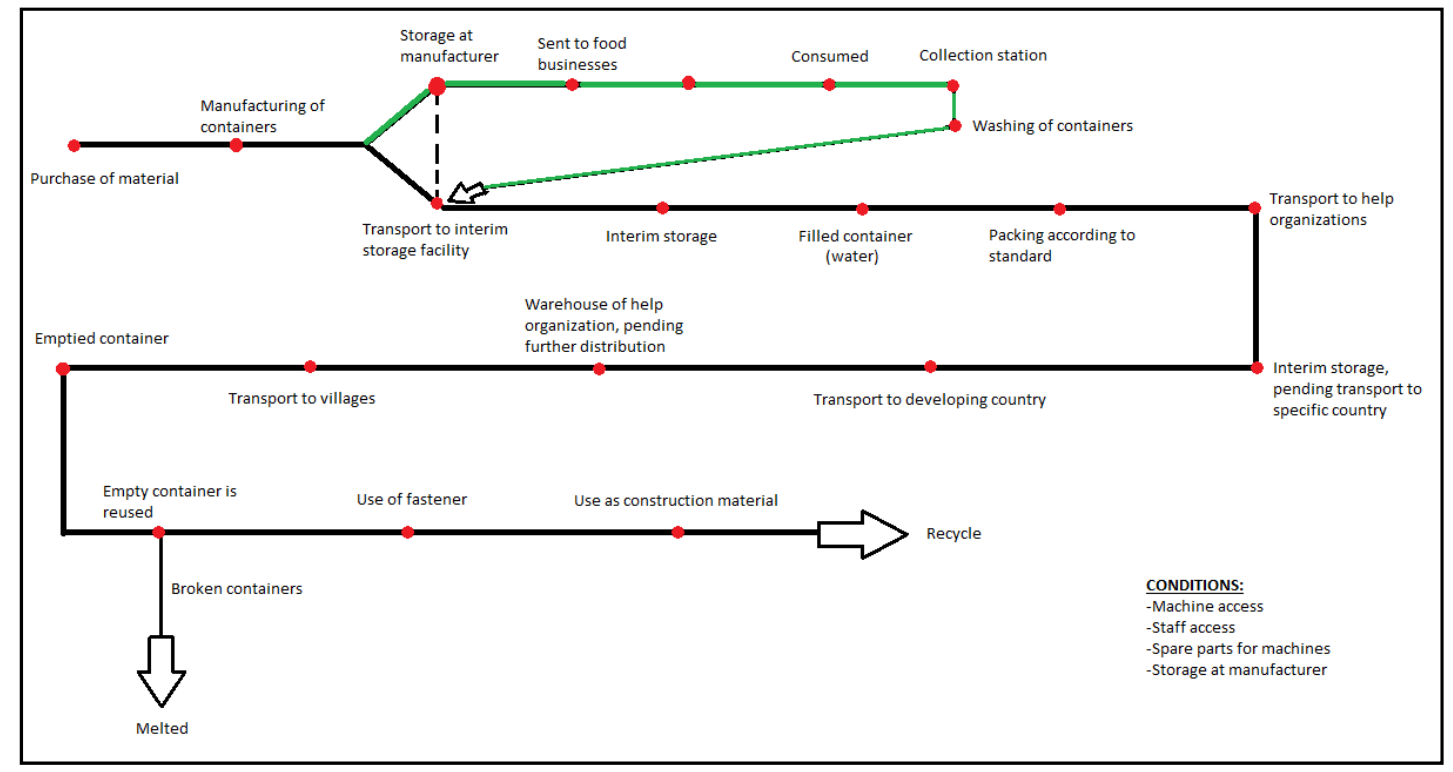

Figure 8. The lifecycle mapping performed by the students of the liquid container project. 
A large number of steps, through which the product passed during its life cycle was identified. For each of these steps, the students identified stakeholders and their specific demands on the product. This enabled the student group to prepare a requirement specification varying over time. For example, during manufacture, there are also requirements related to the processability of the product and for the use of the product (when transporting or storing water) there are other requirements, such as toxicity, permeability etc where the software was useful for fact-finding. The different demands on the product, through its life cycle, were then compared to existing/competing products in order to identify product features not previously covered. This process enabled the students to identify an opportunity to an improved design that could be competitive on the market.

Potential customers were interviewed. Similar products were analysed and legal requirements identified through the study of relevant EU-directives. At this stage the software proved very helpful for the students through its limit stage selector (see Figure 9) providing the students with a list of material properties and where each property either directly or indirectly corresponds to one or more requirements on the product. It is well known that customers do not always know what they want, and find it difficult to articulate what they want in a way that translates to technical specifications. Therefore this list helps the students to find requirements not specifically addressed by customers or by competitors.

The list of requirements identified by the group greatly exceeded what other groups in the class managed to identify in terms of quality and level of detail. The advantage of using the limit stage selector tool this way was explicitly expressed by the students themselves. They also articulated the advantage of having easy access to explanatory Science Notes of the software, such as how material properties are measured or tested and which design considerations should be made. 


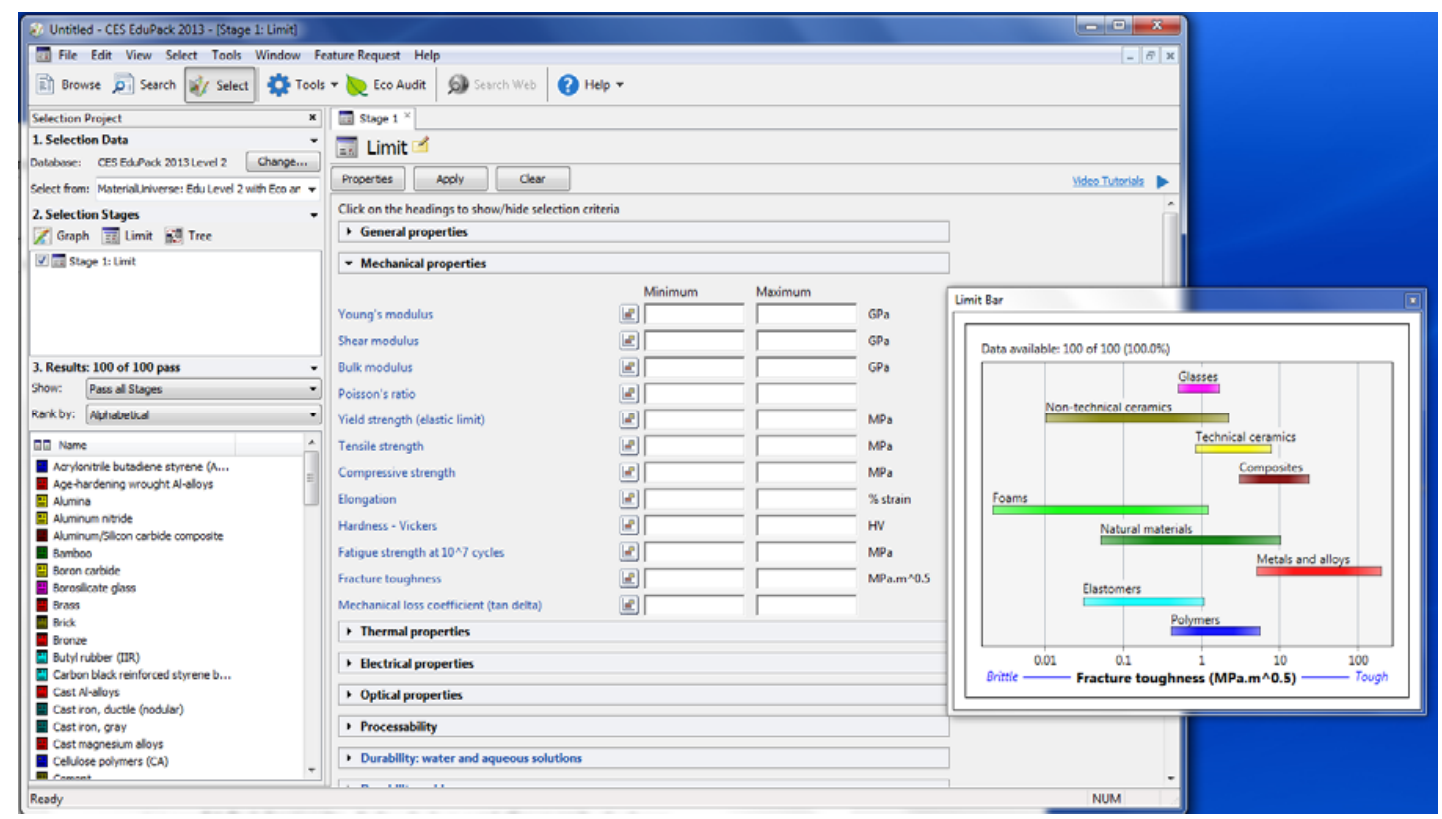

Figure 9. Screen dump showing part of the Limit Stage property listing, including existing ranges of values in the Materials database for guidance.

In parallel to identifying requirements the group started searching for ideas and possible solutions. The software was not used at this stage, instead, methods such as Brainstorming, searches in Patent databases, TRIZ ${ }^{13}$ effects databases etc were used. However, at a later stage of the project, when the concept was to be refined, the software was extensively used and new ideas came up. The students then realized that the software could have been used earlier as a basis for finding new ideas as well.

\subsection{Selection of concepts}

\section{Potential use of the software}

After a number of concepts have been created, a screening and ranking process begins, in order to determine which concept(s) to develop further. Even at an early stage, material cost or properties like fracture toughness or optical transparency can guide the consideration of concepts. It is therefore a huge advantage to have a concise, coherent and reliable source of data compiled in the software. A good database should provide access to properties of all material families; polymers, elastomers, glasses, ceramics, metals and hybrids, see Figure 10. This is crucial when it comes to comparing and selecting concepts or materials. 


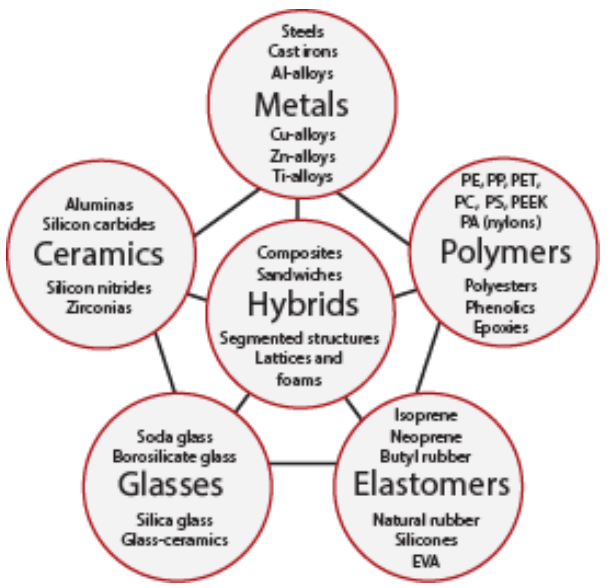

Figure 10. Schematic picture of the material families represented in CES EduPack ${ }^{3}$

A particular class of properties that could be in focus when selecting concepts are the Eco properties. These are relevant, in particular, when applying Design for Environment or Design for Sustainability methodologies, see Figure 11.

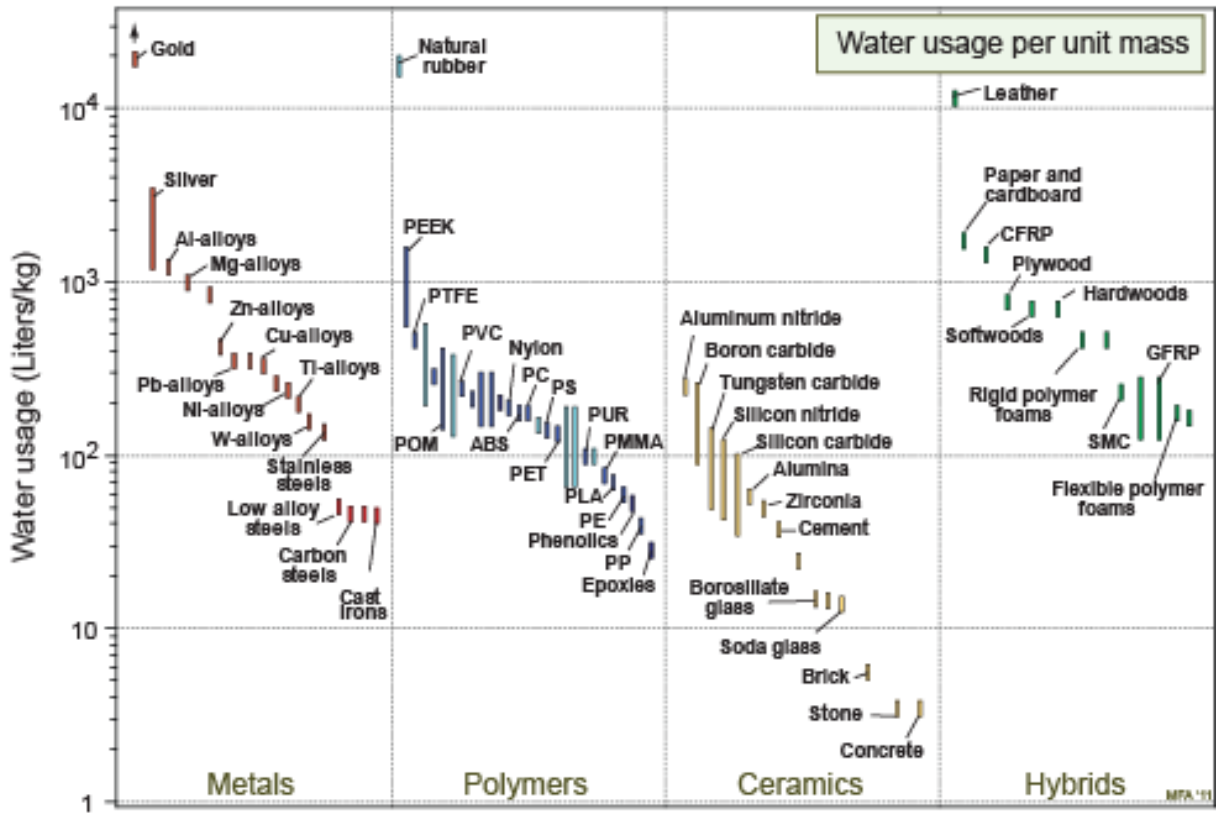

Figure 11. Example of a chart that might inspire re-engineering by Design for Sustainability.

\section{Student case study}

When the design requirements were established and the students had finished identifying possible product concepts, the first step was to screen all solutions in order to identify concepts that did not meet the essential requirements. These concepts were reviewed to see if they could be altered to meet the requirements - and eliminated only if this wasn't possible. After this first 
screening, 52 concepts ideas remained and continued to a second screening. In this process the concepts were compared to a selected reference in order to identify and rank the most favourable or promising solutions. The software at this stage offered the students easy access to consistent material data, as necessary for comparison.

After the second screening, 17 concepts were identified and passed on to a ranking using a Kesselring Weighted Criteria Matrix ${ }^{14}$, which takes into account the relative importance of criteria, see Table 1 . The students identified two preferred solutions that were subjected to a more detailed analysis including an eco-analysis as well as a product cost estimation based on selected materials and manufacturing methods. Again, the software was extensively used and allowed the students to explore large numbers of materials and manufacturing methods within a limited time frame. One solution was identified for continued work in order to optimize the design, as described in the following section.

Table 1. Kesselring Weighted Criteria Matrix ${ }^{14}$ for the student project.

\begin{tabular}{|c|c|c|c|c|c|c|c|c|c|c|c|c|c|}
\hline \multirow[b]{2}{*}{ Selection Criteria } & \multirow{2}{*}{$\begin{array}{l}\text { Weight } \\
\text { (Total } \\
100 \% \text { ) }\end{array}$} & \multicolumn{2}{|c|}{ R1 (Reference) } & \multicolumn{2}{|r|}{ R4 } & \multicolumn{2}{|c|}{54} & \multicolumn{2}{|c|}{ T06 } & \multicolumn{2}{|c|}{ Vac3 } & \multicolumn{2}{|c|}{ Vac4 } \\
\hline & & $\begin{array}{l}\text { Score } \\
(1.5)\end{array}$ & $\begin{array}{c}\text { Weighted } \\
\text { Score }\end{array}$ & $\begin{array}{l}\text { Score } \\
(1-5)\end{array}$ & $\begin{array}{c}\text { Weighted } \\
\text { Score }\end{array}$ & $\begin{array}{l}\text { Score } \\
(1.5)\end{array}$ & $\begin{array}{c}\text { Weighted } \\
\text { Score }\end{array}$ & $\begin{array}{l}\text { Score } \\
(1.5)\end{array}$ & $\begin{array}{c}\text { Weighted } \\
\text { Score }\end{array}$ & $\begin{array}{l}\text { Score } \\
(1.5)\end{array}$ & $\begin{array}{c}\text { Weighted } \\
\text { Score }\end{array}$ & $\begin{array}{l}\text { Score } \\
(1.5)\end{array}$ & $\begin{array}{l}\text { Weighte } \\
\text { d Score }\end{array}$ \\
\hline Stability & 16 & 3 & 0,48 & 4 & 0,64 & 5 & 0,8 & 2 & 0,32 & 3 & 0,48 & 4 & 0,64 \\
\hline Low $\mathrm{CO}^{2}$-emissions (manufacturing) & 10 & 4 & 0,4 & 4 & 0,4 & 2 & 0,2 & 3 & 0,3 & 1 & 0,1 & 1 & 0,1 \\
\hline Lightweight & 10 & 3 & 0,3 & 3 & 0,3 & 3 & 0,3 & 4 & 0,4 & 3 & 0,3 & 3 & 0,3 \\
\hline Low CO2-footprint (filled) & 8 & 4 & 0,32 & 4 & 0,32 & 3 & 0,24 & 4 & 0,32 & 3 & 0,24 & 3 & 0,24 \\
\hline Fastening possibilities & 10 & 2 & 0,2 & 3 & 0,3 & 5 & 0,5 & 4 & 0,4 & 4 & 0,4 & 2 & 0,2 \\
\hline Compact (filled) & 6 & 3 & 0,18 & 3 & 0,18 & 3 & 0,18 & 3 & 0,18 & 3 & 0,18 & 3 & 0,18 \\
\hline Stackable (filled) & 8 & 2 & 0,16 & 3 & 0,24 & 3 & 0,24 & 3 & 0,24 & 3 & 0,24 & 4 & 0,32 \\
\hline Compact (prefilled) & 6 & 1 & 0,06 & 1 & 0,06 & 4 & 0,24 & 4 & 0,24 & 4 & 0,24 & 4 & 0,24 \\
\hline Stackable (prefilled) & 5 & 2 & 0,1 & 3 & 0,15 & 4 & 0,2 & 3 & 0,15 & 3 & 0,15 & 2 & 0,1 \\
\hline Low $\mathrm{CO}_{2}$-footprint (prefilled) & 4 & 1 & 0,04 & 1 & 0,04 & 4 & 0,16 & 4 & 0,16 & 4 & 0,16 & 4 & 0,16 \\
\hline Recyclability & 7 & 5 & 0,35 & 5 & 0,35 & 2 & 0,14 & 4 & 0,28 & 3 & 0,21 & 2 & 0,14 \\
\hline Easy to assemble & 6 & 3 & 0,18 & 4 & 0,24 & 3 & 0,18 & 2 & 0,12 & 4 & 0,24 & 3 & 0,18 \\
\hline Isolation & 4 & 4 & 0,16 & 4 & 0,16 & 3 & 0,12 & 4 & 0,16 & 4 & 0,16 & 4 & 0,16 \\
\hline Total & 100 & & 2,93 & & 3,38 & & 3,5 & & 3,27 & & 3,1 & & 2,96 \\
\hline Rank & & \multicolumn{2}{|c|}{11} & \multicolumn{2}{|r|}{2} & \multicolumn{2}{|c|}{1} & \multicolumn{2}{|r|}{4} & \multicolumn{2}{|r|}{5} & \multicolumn{2}{|c|}{9} \\
\hline Continue (Yes/No/Combine) & & & & \multicolumn{2}{|c|}{ Combine } & \multicolumn{2}{|c|}{ Yes } & & & & & & \\
\hline
\end{tabular}

3.3 Optimization of properties for the final design, including manufacturing selection and costing

\section{Potential use of the software}

The development of a concept is rarely as simple and linear as suggested by Figure 1 . Optimization of properties is rather a highly iterative process, which involves finding the best combination of material and manufacturing process with respect to cost and performance, as suggested in Figure 12. This is a core functionality of the software (see Figure 3) which is based on a systematic selection procedure and support for advanced methods, such as using Performance Indices. 


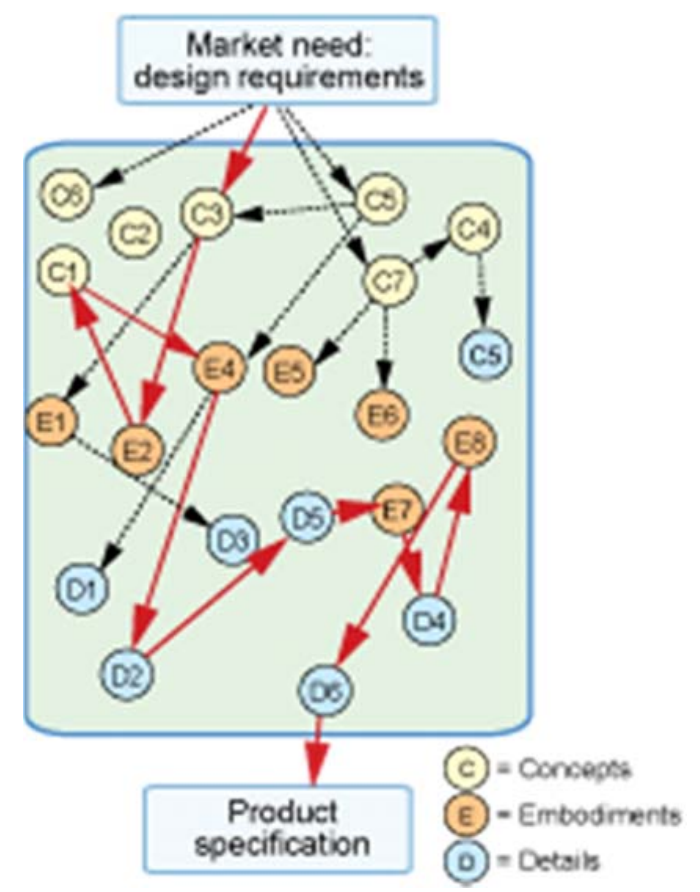

Figure 12. The non-linear nature of the design process $^{3}$.

One of the useful features of the software is the links between materials and process data. This enables the students to have a list of theoretically possible manufacturing processes linked to certain materials or, vice versa: materials that can be processed (theoretically) using a certain manufacturing method. This enables useful knowledge from previous materials and manufacturing courses to be applied in product development or capstone projects.

Whereas function is specified very early in the technical design process and shape might be determined at the concept generation, the strongly linked choices of material and manufacturing processes is typically part of the optimization stage. This particular software allows for some flexibility to select materials based on manufacturability or cost. This facilitates Design for Manufacturability or Design for Value approaches to be explored. All the above mentioned aspects-Function, Shape, Material and Process-are, however interlinked, as shown previously in Figure 2, and must be consider together before the final design. Once the combination of materials and processes is clearer, an estimate of the total costs can be made, using the built-in cost model, see Figure 13. 


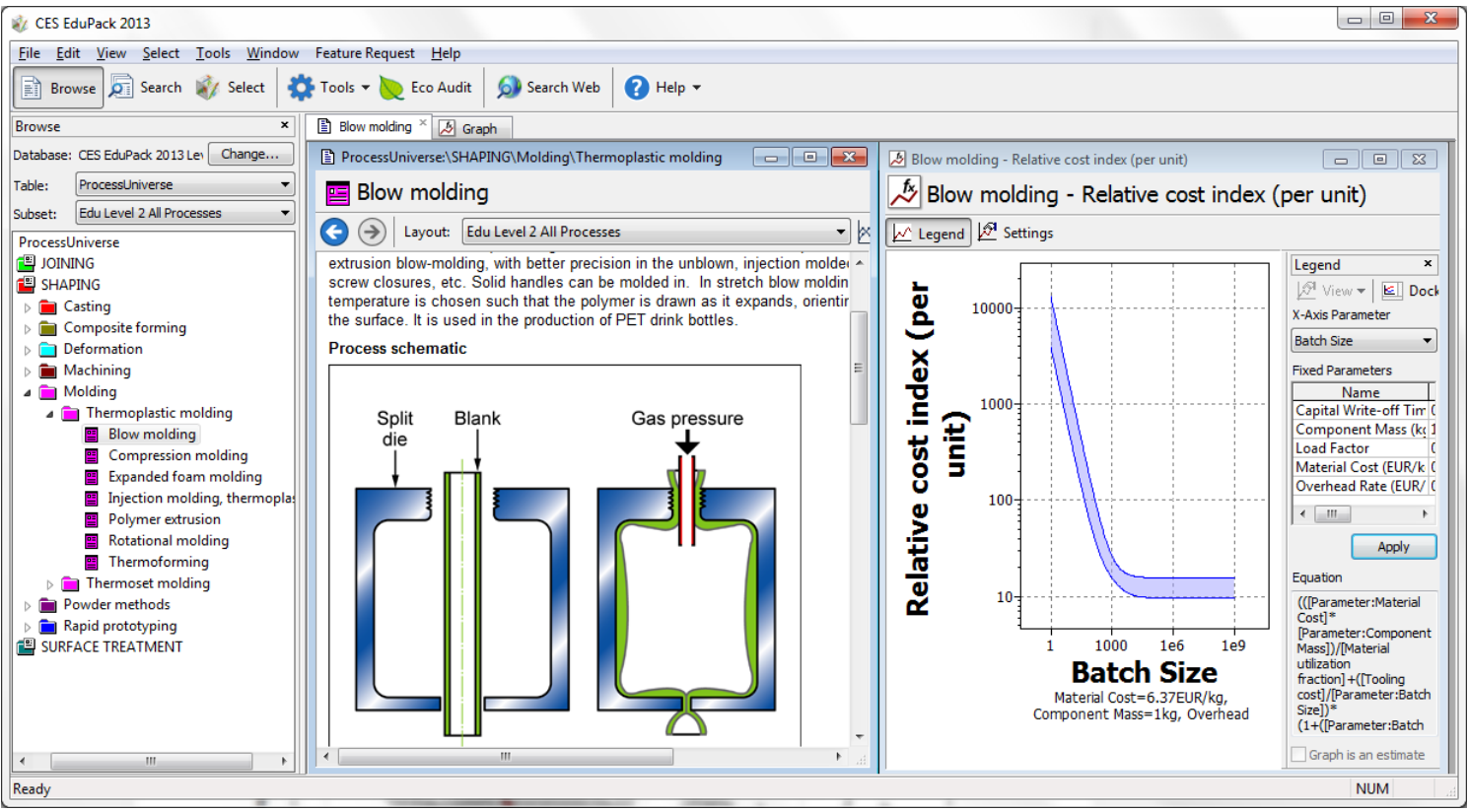

Figure 13. Example of a cost model in the software for blow molding, considered in the case.

\section{Student case study}

The software was extensively used for optimization of the chosen concept. Selecting the best material and manufacturing method helps a product to perform its function and meeting all the requirements at a favourable cost. This is a substantial task, given the abundance of materials considered, see Figure 14. It includes exploring many materials and analyzing them from a performance as well as manufacturability, cost and eco-perspective. This was made possible by the students identifying an efficient and standardized working process, enabling them to work in parallel, thus covering more combinations of materials and processes. Using the same database and working with the same process ensured that the results obtained were consistent and could be compared. An extensive use of performance indices also helped in the material selection. 


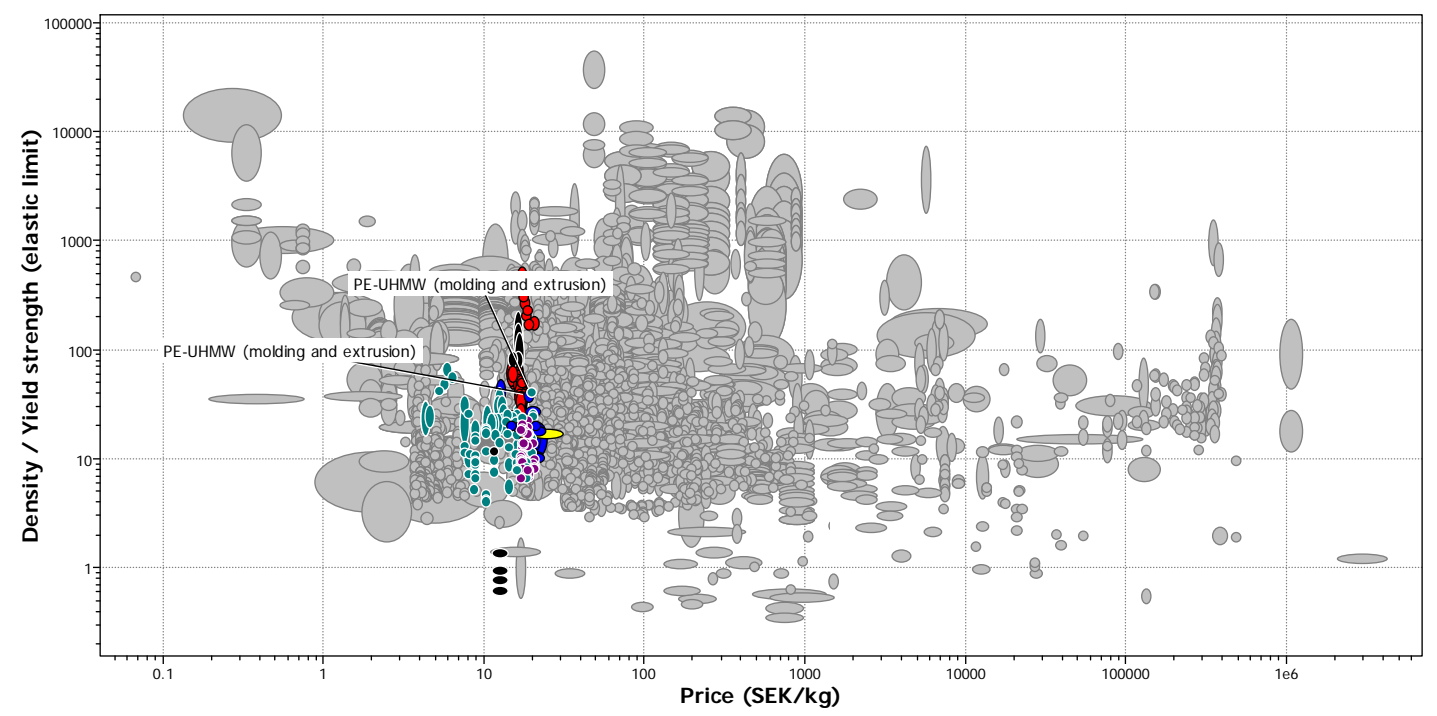

Figure 14. Example of a chart used by students to optimize a combined property (Density/Strength) against Price. Gray bubbles represent materials that failed screening.

\subsection{Evaluation of properties of the final product}

Potential use of the software

Whereas, for example, cost, strength, stiffness and weight usually appear as constraints or design objectives, there are important properties of a product which may not be part of the concept selection or may not be explicitly considered in the design requirements. If the focus is on mechanical performance, eco and durability properties, which both relate to sustainability, might be neglected or overshadowed by cost considerations. These properties can nevertheless be considered around the time of product specification, both in teaching and in real life. A better solution may be presented to someone in higher management who might be able to authorise a higher cost, knowing that the market would accept it for additional benefits. When the final material and manufacturing process selection is made, it is still possible to examine life cycle perspectives and compliance with future product legislation, for example concerning toxicity and recycling. An Eco Audit of the final design is always useful, even if eco properties have been considered in early design stages. Embodied energy and Carbon footprint of chosen materials and processes or Durability performance can also be used to find arguments for marketing or labelling purposes (Eco-friendly, Heavy duty, etc).

A property mapping of the final design in relation to alternative materials can generate ideas for further development. It may also at post product design be possible to replace materials with a more durable or "greener", but otherwise equivalent materials for marketing purposes, such as to respond to previously unknown needs. 


\section{Student case study}

The last step in the project was for the students to verify the performance of new products against competitors. This was made using the software as a base giving comparable data for the benchmarking. Key material properties as well as material costs and eco-performance were compared, see Figure 15. The results indicated that the new product would be superior to the existing in most aspects and should therefore be competitive on the market.

This comparison was properly documented in the form of diagrams and could later on easily be used as a basis for, e.g., developing marketing strategies and preparing sales material.

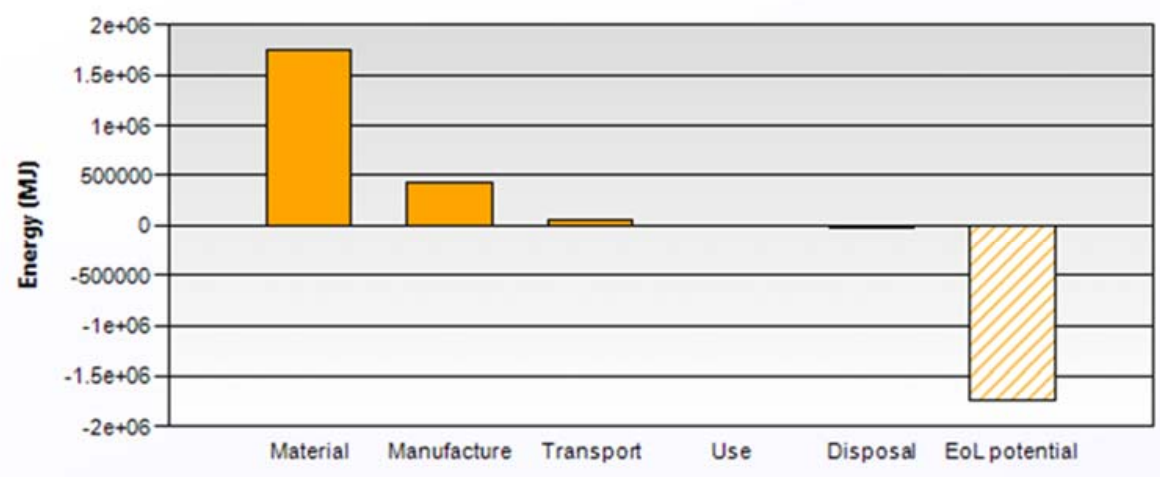

Figure 15. Distribution of embodied energy over lifecycle phases of the product (Eco Audit)

\subsection{Examination results of the students}

After assessment of the students taking the course, it was found that the group that was monitored using CES EduPack extensively, performed better than other groups in several aspects:

The requirement specifications that were used as a basis for the development were more thoroughly elaborated, had more requirements and better target values. During the meetings with the examiner, it could also be noted that the students understanding of material properties and their impact on product performance was better than other students in the class. The availability of material data also enabled these students to perform better in terms of materials selection exploring more alternatives than other student groups.

Another area were the group performed significantly better than other groups was in costing. The easy access to material cost data in combination with information on costs related to manufacturing processes enabled the group to make proper cost evaluations of more material/processing options than other groups. This information was used by the student in the concept selection stage of the project and enabled the group to make a better founded selection than other groups in the class. 
The extensive use of the software did however not help the students in improving their overall understanding of and ability in planning, execution and presentation of a development project when compared to other students in the class.

\section{Summary and conclusions}

If we summarize the various capabilities of the software in a teaching context, we find: extensive access to data on properties of all material families; polymers, ceramics, alloys and hybrids as well as information on manufacturing processes, integrated cost models, selection tools and an Eco Audit tool. These can be useful for many different directions within product development, for example Design for $X$ (DfX) which is commonly used to represent different design focuses. In particular, X could stand for Manufacturability or Environment in our approach.

The case study was limited to one group out of eight in a course. All groups had access to the software but only the group studied in this work, was urged to use the software as the main tool. All groups had decided to work on different assignments which makes a quantitative analysis of the results difficult (impossible). One of the findings, which can not alone be taken as proof for the success of the approach, was that the group monitored in the case study performed very well in comparison to other groups in the class, as assessed by the instructor.

The students expressed the advantage of having easy access to explanatory information, such as how to measure or test material properties and design considerations to be made, which is available in Science Notes integrated with the software. This could be used as an interactive textbook and enhanced their understanding of materials science and facilitated design considerations linked to different types of materials.

In addition to the above, this study highlighted the following: The use of a common comprehensive database that supports many different aspects of the product development process inspired the group to develop their own standardized procedures enabling them to work in an efficient way. This in combination with easy access to consistent data gave students time to more thoroughly explore parts of the development process, such as requirements identification and competitor analysis. It also made it possible to more thoroughly analyze combinations of materials and manufacturing processes, thus reaching a more well founded suggestion for a new product. This increased the satisfaction felt by the group members, as expressed by themselves, after concluding the work.

The requirements on documentation is often expressed by students as being a burden. However the support for this given by the software has been appreciated and perceived as very positive 
and therefore contributed to the willingness of students to perform an extended and deeper evaluation.

Their creativity in terms of generating unique solutions did not exceed what other groups managed to do. One explanation could be that the group realized the advantages of using material properties as an input to new ideas too late in the project.

Based on the results of this study our conclusion is that several key elements of a Product Development process can be facilitated and taught using, for example, the Standard Edition of the widely used CES EduPack software.

The main contributions from the software, which were explored in the case, support:

i. Specification of product function and requirements, using the limit stage parameters as guidelines for properties to consider.

ii. Screening and scoring (ranking) of concepts, where material properties, such as strength or cost for concepts can be estimated using the software.

iii. Optimization of properties for the final design including process selection and costing, is a core functionality, finding the best metal alloy or grade of polymer. It can be performed using links between materials and process data, in combination with built-in cost models.

iv. Evaluation of properties of the final product to be used by marketing, which could consist of declaring the carbon footprint using an Eco audit, for example. The software could also be used to analyse competitor products in order to find strengths and weaknesses with the new product to be used as a basis for strategic market positioning.

\section{References}

1. Pahl, G., Beitz, W., Feldhusen, J., Grote, K.H. (2007), Engineering design: a systematic approach. Springer 3:d ed., translated by K. Wallace and L. Blessing, The Design Council, London, UK and Springer-Verlag, Berlin, Germany. ISBN 978-1-84-628318-5.

2. Ulrich K T and Eppinger S D, Product Design and Development, McGraw Hill, 5.ed. 2012

3. Ashby, M. F., Materials Selection in Mechanical Design (4th edition) Butterworth Heinemann, 2011.

4. van Vliet, J.W., Design for Manufacturing, PhD Thesis (2001), Delft University, the Netherlands.

5. Granta Design homepage, URL: http://www.materials-education.com (

Accessed February 10, 2014)

6. Albinana, J.C., and Vila, C., A Framework for concurrent material and process selection during conceptual product design stages, Materials and Design 41 (2012) 433-446.

7. The Bologna Process, <www.ehea.info> (Accessed January 3, 2014).

8. Biggs, J., Teaching for Quality Learning at University, 2:nd ed., The Society for Research into Higher Education and Open University Press, Berkshire: England, 2003. 
9. Eason, P., Achieving ABET Outcomes 'h’ through ‘k’ Using CES EduPack Eco Audit, Proceedings of the 4:th North American Materials Education Symposium, URL: http://www.materials-education.com, free, 2013.

10. Sharif Ullah, A. M. M., Significance of Materials Selection Tools in Undergraduate Engineering Education, Proceedings of JSEE Annual Conference, 2011, Sapporo, Sept. 9, 2011.

11. Anderson, L.W. (Ed.), Krathwohl, D.R. (Ed.), Airasian, P.W., Cruikshank, K.A., Mayer, R.E., Pintrich, P.R., Raths, J., \& Wittrock, M.C. (2001). A taxonomy for learning, teaching, and assessing: A revision of Bloom's

Taxonomy of Educational Objectives (Complete edition). New York: Longman.

12. "Skills-Knowledge-Attitudes", https://tll.mit.edu/help/teaching-materials-0 (accessed January 3, 2014).

13. Altshuller, G., Creativity as an Exact Science, (Gordon and Breach, NY 1988). Translated from Russian by Anthony Williams).

14. Kesselring F., Technische Kompositionslehre (Study of Technical Composition), (Berlin/Heidelberg: SpringerVerlag, 1954). 